\title{
Infografia multimídia: uma experiência de produção na graduação em jornalismo
}

\author{
Multimedia infographics: an undergraduate production experience in journalism
}

Ariadna Thalia Zortéa Braz, Rafaella Lopes Pereira Peres

jornalismo visual; infografia multimídia; projeto experimental; gênero

O presente artigo descreve o processo produtivo da infografia multimídia "Corpos Prescritos", produzida como Projeto Experimental para Conclusão de Curso (TCC) de Bacharelado em Jornalismo na Universidade Federal de Mato Grosso do Sul (UFMS), considerada a relação intrincada entre imagem, texto e formas na produção jornalística. A metodologia projetual utilizou como referência os modelos propostos por Ary Moraes e Bruce Archer, com contribuições significativas à experimentação, compartilhamento de conteúdo, à necessidade de entender a infografia como produto do Design da Informação e como resultado de um processo transdisciplinar.

visual journalism; multimedia infographics; experimental design; gender

This article describes the production process of the multimedia infographics "Prescribed Bodies", produced as an Experimental Project for the Conclusion of a Bachelor Course in Journalism at the Federal University of Mato Grosso do Sul (UFMS), considered the intricate relationship between image, text, and forms in journalistic production. The design methodology used as reference the models proposed by Ary Moraes and Bruce Archer, with significant contributions to experimentation, content sharing, the need to understand infographics as a product of Information Design and as a result of a transdisciplinary process.

\section{Introdução}

A infografia se estabelece a partir de uma relação intrínseca do binômio imagem e texto, com a intenção de facilitar a compreensão de assuntos complexos que dificilmente conseguiriam ser explicados somente com o suporte da linguagem verbal. Ainda que tenham esse estigma de simplificação, contudo, não é possível limitar os infográficos à síntese de conteúdos complexos (Lima, 2015). A infografia é, portanto, "um artefato produzido no intuito de comunicar uma mensagem, e que resulta de uma interpretação dos dados contextualizados visualmente através da integração de texto, imagens e/ou formas" (Carvalho e Aragão, 2012).

Para iniciar a discussão, compreendemos a infografia como um artefato do Design da Informação (DI) e que é a natureza da informação apresentada que a configura como jornalística (ou não). Neste caso, os infográficos conformam o que alguns autores chamam de "jornalismo visual e devem se orientar pelos mesmos padrões éticos que se aplicam a outras

Anais do $10^{\circ} \mathrm{CIDI}$ e $10^{\circ} \mathrm{CONGIC}$

Kelli C.A.S. Smythe, Rafael de Castro Andrade (orgs.)

Sociedade Brasileira de Design da Informação - SBDI

Curitiba | Brasil | 2021
Proceedings of the $10^{\text {th }} \mathrm{CIDI}$ and $10^{\text {th }}$ CONGIC

Kelli C.A.S. Smythe, Rafael de Castro Andrade (orgs.)

Sociedade Brasileira de Design da Informação - SBDI Curitiba | Brazil | 2021 
áreas da atividade" (Cairo e Giner, 2011). Assim, a narrativa infográfica deve pressupor uma relação evidente com o que se compreende como realidade e seguir, por princípio, técnicas e formatos sócio-culturalmente aceitos (Teixeira, 2009).

Consideradas essas conceituações, o presente artigo apresenta o processo produtivo de um Projeto Experimental de Conclusão de Curso (TCC) de Bacharelado em Jornalismo da Universidade Federal de Mato Grosso do Sul (UFMS), apresentado em novembro de 2019 e denominado "Corpos Prescritos: infografia multimídia sobre a construção social de gênero"; que objetivou conceituar termos como "sexo biológico", "identidade de gênero" e "orientação sexual", além de apresentar (e questionar) implicações de valores, normas e comportamentos considerados apropriados para homens e mulheres.

Inicialmente, o problema identificado foi o excesso de informações acerca do tema e a dificuldade de conectar o conhecimento produzido em pesquisas científicas com a sociedade como um todo. Especialmente por conta do entendimento das instituições de ensino públicas como espaços de experimentação comprometidos com a popularização da ciência, este infográfico buscou propor reflexões sobre os resultados produzidos a partir da união entre jornalismo, ciência e design, tanto no âmbito da formação profissional, quanto do ativismo social.

Ainda, apesar da infografia ser comumente explorada em veículos de comunicação de abrangência nacional, observamos nos veículos de comunicação de Mato Grosso do Sul uma rara utilização deste produto do jornalismo visual. Até maio de 2019, a monografia de Marques (2017) era o único Projeto Experimental sobre infografia apresentado ao longo dos 30 anos de existência do curso de Jornalismo da UFMS. Portanto, Corpos Prescritos foi o primeiro projeto no curso a abordar o Design da Informação a partir da perspectiva da produção.

O objetivo deste artigo é descrever o processo produtivo da infografia multimídia citada, considerados os efeitos positivos deste processo experimental na construção de um entendimento da visualidade e da relação intrincada entre imagem e texto na produção jornalística. Pretende-se pontuar os procedimentos metodológicos da criação e os resultados da produção de "Corpos Prescritos". Não é objetivo deste artigo, por conta da limitação de espaço, aprofundar a discussão teórica a respeito dos conceitos pesquisados, abordados e sintetizados no decorrer da pesquisa de conclusão de curso, que resultou na infografia apresentada neste artigo. Contudo, é importante pontuar que as pesquisas realizadas para apoiar os conceitos de identidade de gênero, sexo biológico, orientação sexual, e em especial, a ideia de construção social da identidade de gênero, se apoiaram em pesquisas científicas como as de Pedro e Veiga (2019), Mendonça e Penteado (2010), Jesus (2012), Colling e Tedeschi (2019), Adichie (2017) e ONU Mulheres, entre outros.

\footnotetext{
${ }^{1} \mathrm{O}$ infográfico está disponível na: Plataforma Readymag para acesso ao infográfico multimídia 'Corpos Prescritos' (BRAZ, 2019).
} 


\section{Abordagem metodológica}

Apesar de "Corpos Prescritos" ser um produto jornalístico, enquanto parte de um projeto experimental de conclusão de curso seguiu uma metodologia inerente à produção científica. Além do levantamento bibliográfico relativo à produção jornalística e infográfica, bem como os procedimentos jornalísticos necessários à produção de conteúdo jornalístico, se baseou em pesquisas e orientações metodológicas de outros projetos desenvolvidos no âmbito do Jornalismo Visual.

O fazer infográfico neste processo optou por uma linha de pensamento baseada em esquemas não-lineares e com feedbacks constantes, tendo como referência o modelo proposto por Ary Moraes (2013, p.68) e o modelo de Bruce Archer apresentado por Fuentes (2006, p.29) como referência da metodologia projetual (Figura 1) criada.

Figura 1 Modelo metodológico criado para o desenvolvimento de uma infografia jornalística multimídia produção das autoras

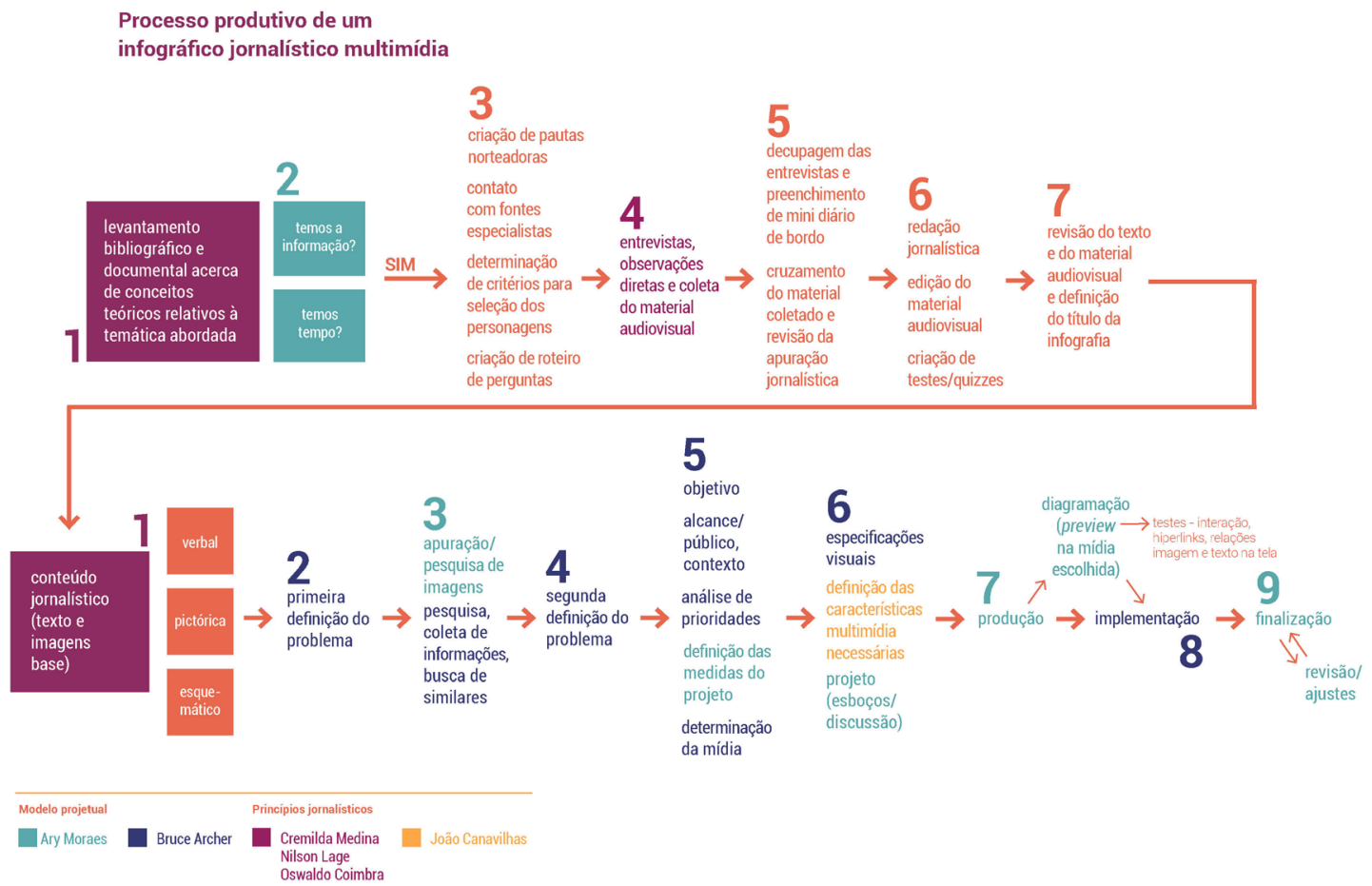

Tendo como problema a complexidade conceitual dos estudos de gênero, o foco produtivo esteve direcionado à sintetização das informações por meio da linguagem infográfica. A tabela abaixo (Tabela 1) apresenta o detalhamento dos procedimentos realizados. 
Tabela 1 passo a passo do processo produtivo do infográfico multimídia "Corpos Prescritos" com o cronograma temporal de construção do artefato final

\begin{tabular}{|c|c|c|}
\hline Etapa & Atividade & Cronograma \\
\hline \multirow[t]{2}{*}{$\begin{array}{l}\text { (1) Levantamento } \\
\text { bibliográfico e } \\
\text { documental }\end{array}$} & $\begin{array}{l}\text { Além dos materiais didáticos e audiovisuais sobre } \\
\text { gênero, os principais suportes teóricos sobre infografia } \\
\text { foram: }\end{array}$ & $\begin{array}{l}\text { Julho a agosto de } \\
2019\end{array}$ \\
\hline & $\begin{array}{l}\text { "Infografia: história e projeto" de Ary Moraes e } \\
\text { artigos de Beatriz Ribas. }\end{array}$ & \\
\hline \multirow[t]{4}{*}{$\begin{array}{l}\text { (2) Produção } \\
\text { jornalística }\end{array}$} & $\begin{array}{l}\text { (a) Foram definidos dois enfoques a serem abordados: } \\
\text { (1) Como pesquisadores e especialistas conceituam } \\
\text { sexo biológico, identidade de gênero e orientação } \\
\text { sexual; e (2) quais as diferenças na criação de meninos } \\
\text { e meninas em famílias de Campo Grande (MS); }\end{array}$ & $\begin{array}{l}\text { Julho a setembro de } \\
2019\end{array}$ \\
\hline & $\begin{array}{l}\text { (b) para atender o primeiro foi realizado levantamento } \\
\text { de pesquisadores de gênero e seus respectivos } \\
\text { trabalhos; }\end{array}$ & \\
\hline & (c) contatadas fontes; & \\
\hline & (d) criado o roteiro de perguntas & \\
\hline $\begin{array}{l}\text { (3) Entrevistas, } \\
\text { observações } \\
\text { diretas e coleta } \\
\text { do material } \\
\text { audiovisual }\end{array}$ & $\begin{array}{l}\text { Foram } 14 \text { entrevistas em vídeo e áudio, sendo dez a } \\
\text { partir do acompanhamento imersivo com famílias e } \\
\text { outras quatro realizadas com especialistas. }\end{array}$ & $\begin{array}{l}\text { Setembro e outubro } \\
\text { de } 2019\end{array}$ \\
\hline $\begin{array}{l}\text { (4) criação do } \\
\text { projeto gráfico }\end{array}$ & $\begin{array}{l}\text { (a) briefing; (b) construção de mapa conceitual; (c) } \\
\text { pesquisa e montagem de painel de referências; (d) } \\
\text { brainstorming; (e) seleção da plataforma digital (f) } \\
\text { criação de esboços ou diagramas visuais da infografia; } \\
\text { (g) definição de quadro de estilos como cores, } \\
\text { tipografias e elementos complementares; e (h) escolha } \\
\text { da artista/encomenda de ilustrações }\end{array}$ & $\begin{array}{l}\text { Setembro e outubro } \\
\text { de } 2019\end{array}$ \\
\hline $\begin{array}{l}\text { (5) edição do } \\
\text { material } \\
\text { audiovisual e } \\
\text { redação } \\
\text { jornalística }\end{array}$ & $\begin{array}{l}\text { (a) Decupagem do material de entrevista; (b) } \\
\text { preenchimento de mini diário de bordo; (c) produção } \\
\text { textual }\end{array}$ & $\begin{array}{l}\text { Setembro e outubro } \\
\text { de } 2019\end{array}$ \\
\hline $\begin{array}{l}\text { (6) produção e } \\
\text { publicação }\end{array}$ & $\begin{array}{l}\text { (a) Diagramação do infográfico em plataforma digital; (b) } \\
\text { revisão do material; (c) entrega do relatório final e } \\
\text { defesa do TCC }\end{array}$ & Novembro de 2019 \\
\hline $\begin{array}{l}\text { (7) divulgação da } \\
\text { infografia } \\
\text { finalizada }\end{array}$ & $\begin{array}{l}\text { Criação de redes sociais e divulgação em eventos } \\
\text { acadêmicos }\end{array}$ & A partir de 2020 \\
\hline
\end{tabular}

\section{Decisões gráficas}

A resposta do briefing permitiu a identificação das principais necessidades e objetivos, destacando as palavras "debate", "conceituação", "pesquisa" e "popularização" a partir da construção de um mapa mental/conceitual (Figura 2), que teve como ponto de partida a palavra 'gênero', desdobrando-se em outros termos. Posteriormente, foram criados painéis de referência (Figuras 3), com imagens pertinentes à (representativas da) conceituação de sexo, gênero orientação e identidade de gênero e alguns esboços estruturais (Figura 4), contendo 
um planejamento de posicionamento de textos, fotos, vídeos, áudios, ilustrações, botões, hiperlinks, entre outros.

Figura 2 Mapa conceitual - produção da autora, set.2019

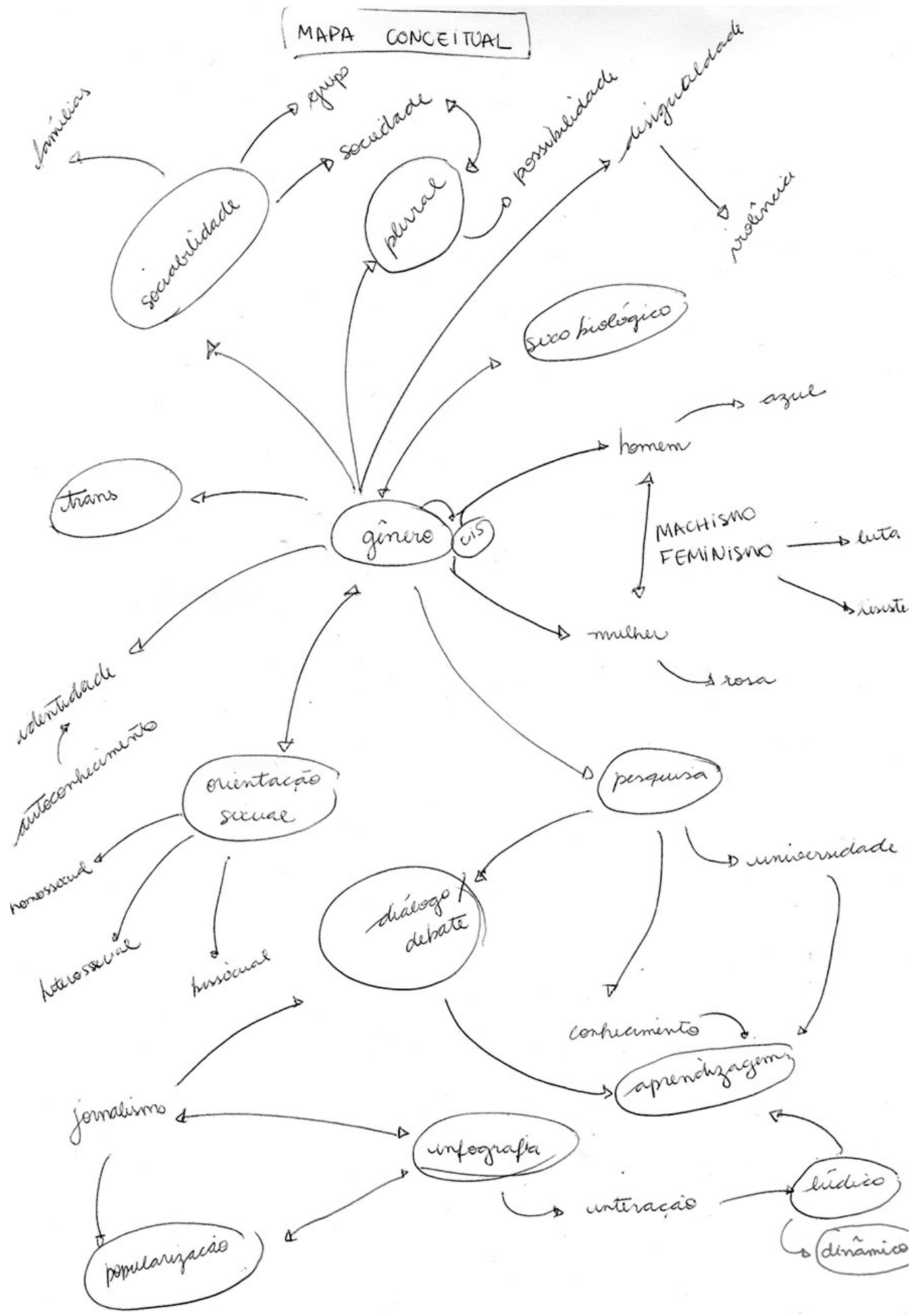


Figura 3 Painel de referências para ilustração de conceituação (1) e definição (2) de "identidade de gênero" - produção da autora, set.2019
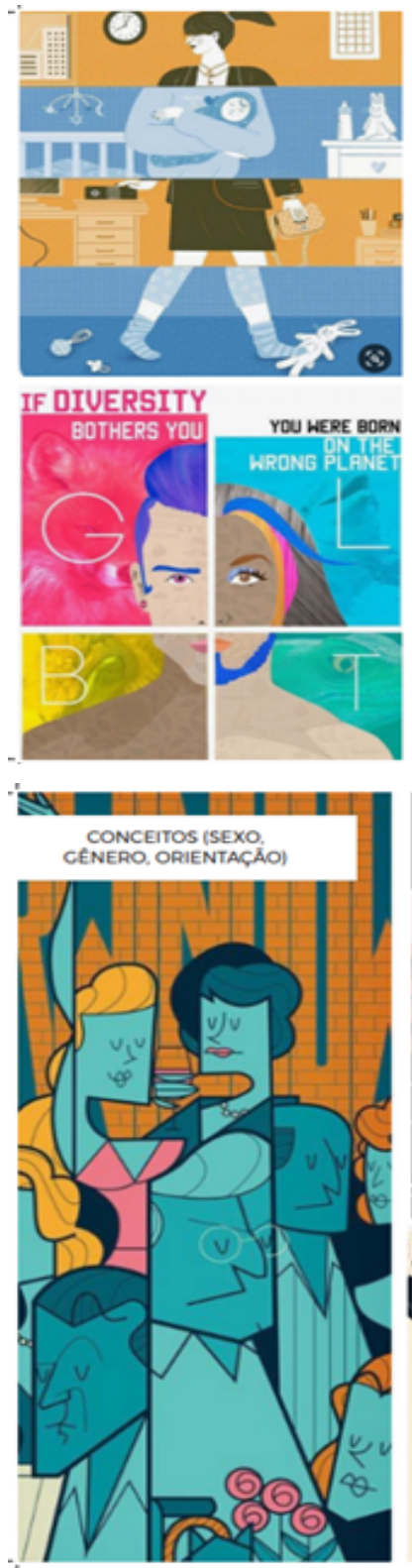
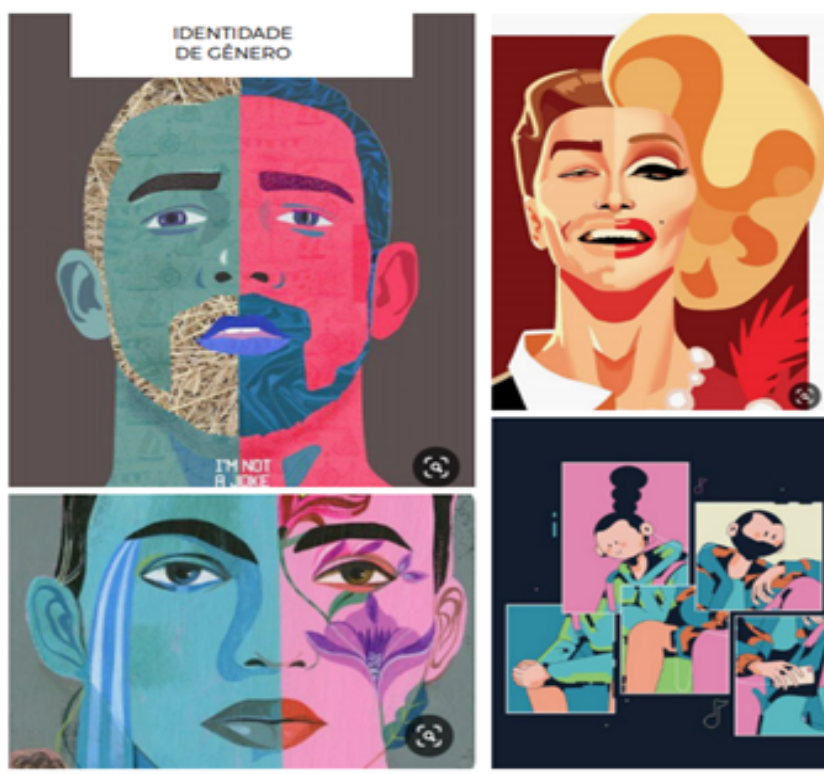

(a)
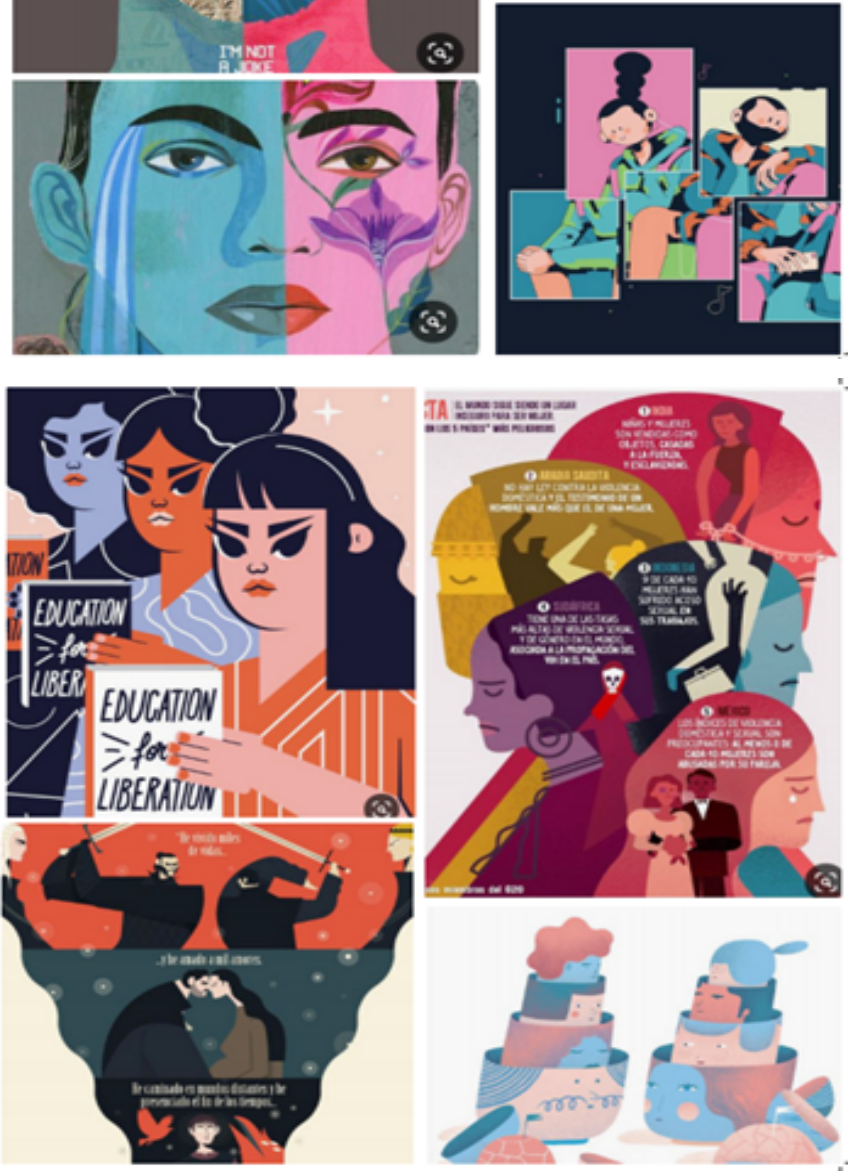
Figura 4 Esboço estrutural para desenvolvimento da ilustração e layout da primeira tela do infográfico produção da autora, set.2019

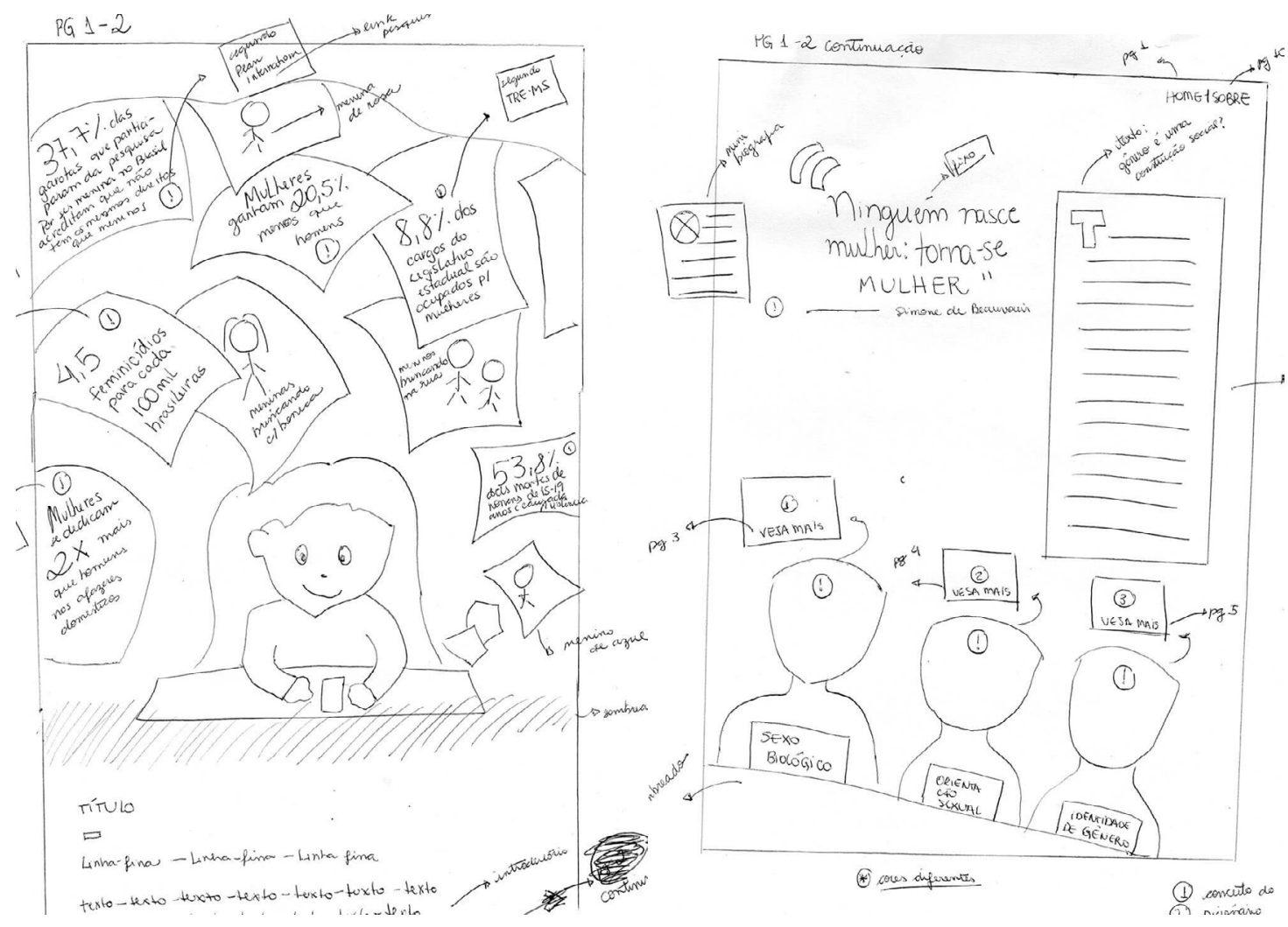

A tela de entrada do infográfico 'Corpos Prescritos', como exposto na Figura 4 (acima), apresenta uma combinação dos principais elementos da narrativa, reforçando o projeto gráfico deste trabalho, a partir do contraste e repetição da paleta de cores triádicas assonantes, pensada para promover equilíbrio e dinamicidade. Neste contexto, vale lembrar que a paleta cromática (Tabela 2) é resultado de um esforço de sair da dicotomia rosa e azul, relacionadas ao feminino e ao masculino.

Tabela 2 Especificação de cores e códigos para publicação digital

\begin{tabular}{lllll}
\hline Cor & $\mathbf{R}$ & $\mathbf{G}$ & B & \# \\
\hline 51 & 169 & 172 & 33a9ac \\
& 255 & 166 & 70 & ffa646 \\
& 248 & 94 & 65 & f85e41 \\
152 & 32 & 98 & 982062 \\
& 52 & 55 & 121 & 343779 \\
\hline
\end{tabular}

As etapas apresentadas resultaram na diagramação da página web onde a infografia multimídia está disponível. O infográfico foi desenvolvido no plano gratuito da plataforma digital ReadyMag, escolhida devido a facilidade de criação sem a necessidade de manipulação da 
linguagem HTML. As limitações, contudo, somadas aos feedbacks de usuários, definiram ajustes e revisões durante a implementação do projeto gráfico.

\section{Resultados gráficos}

Figura 5 Tela de entrada do infográfico - produção da autora, nov.2019

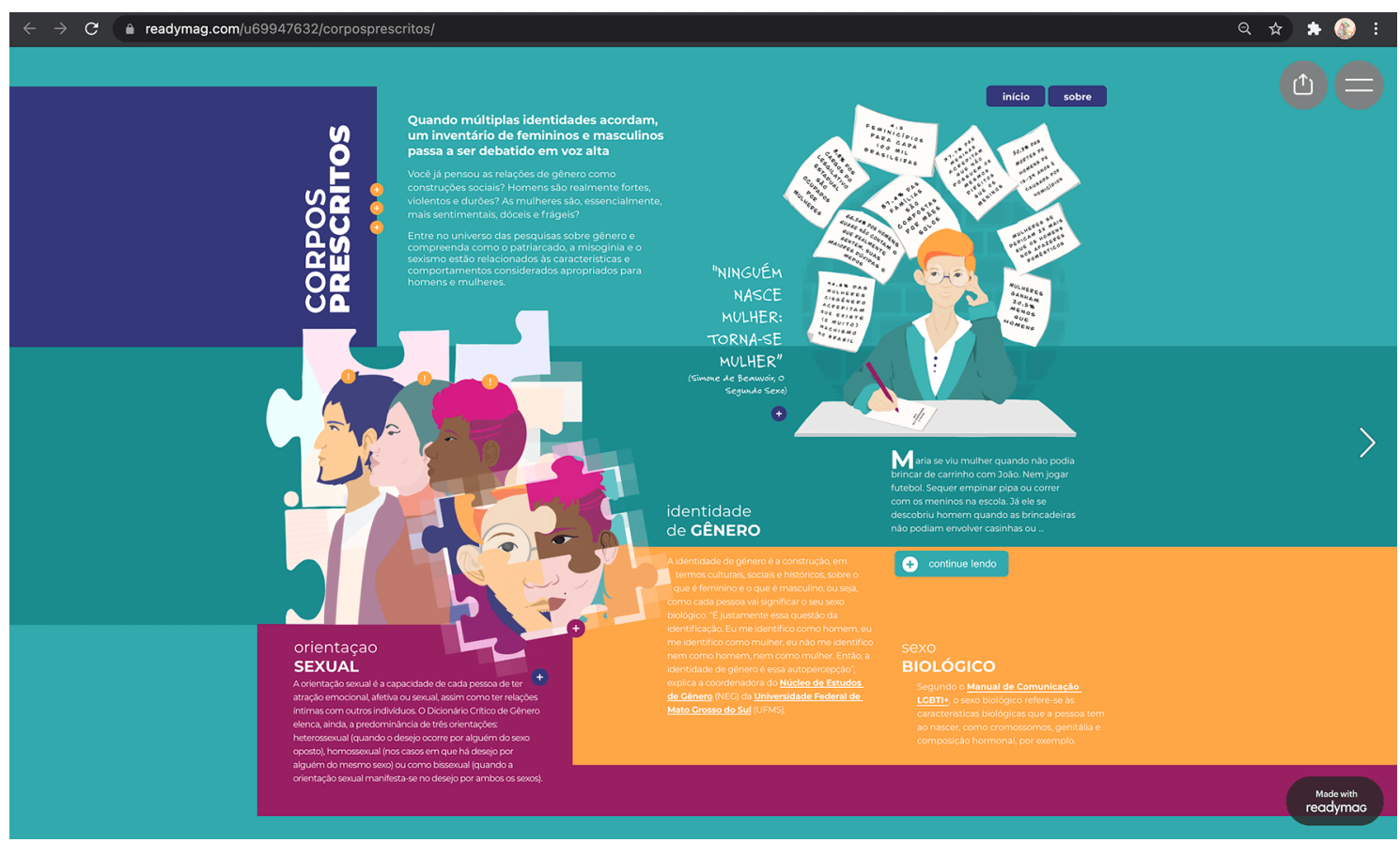


Figura 6 Sequência de informações da tela inicial do infográfico 'Corpos Prescritos' - produção da autora, novembro de 2019
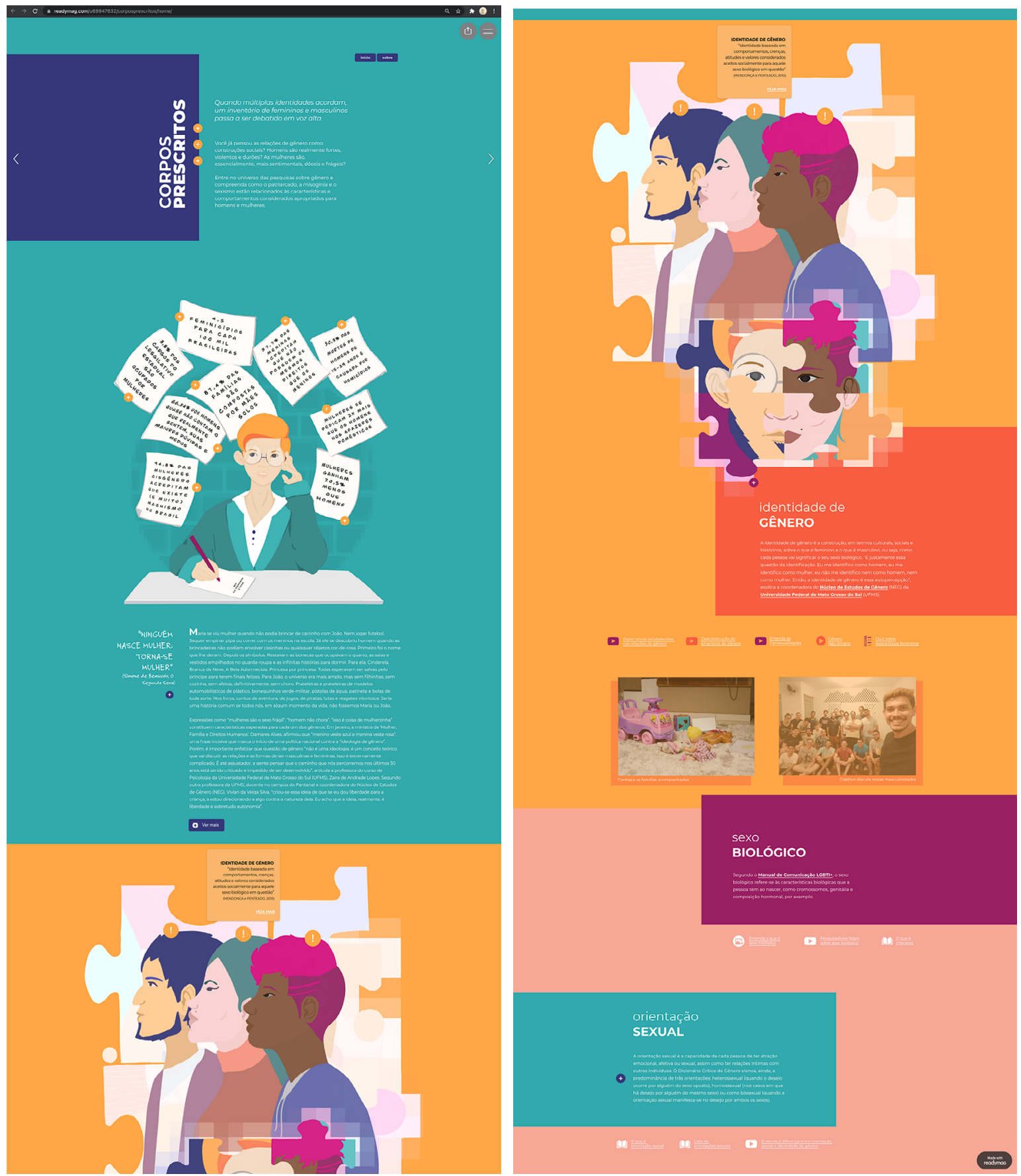

\section{Considerações possíveis}

Os movimentos sociais se potencializaram no espaço público em rede como forma de enfrentamento político, social e/ou cultural. Por meio da conscientização e promoção de uma causa, como o papel da família na reprodução da dominação masculina e a consequente desigualdade entre homens e mulheres, a apresentação infográfica deste tema se apoia na ideia de que ela pode "tornar claro aquilo que é complexo e talvez não haja nada mais urgente no atual momento histórico" (Moraes, 2013, p. 16). 
Considerando os resultados, o infográfico apresentado propõe a reflexão dos conceitos e definições englobados na discussão do tema, especialmente por conta da repercussão após a divulgação, o aceite para publicação/colaboração na Revista Empodere e os prêmios regional e nacional da Exposição de Pesquisa Experimental em Comunicação (EXPOCOM) 2020.

Ademais, sua veiculação na internet é relevante diante da importância do assunto. 0 jornalista, enquanto profissional da mídia e perante os princípios deontológicos que o cerca, "tem chances potenciais para atrair a atenção do público-leitor à reflexão acerca da construção das desigualdades sociais, mapeando possíveis gatilhos para a quebra de convenções, estereótipos e paradigmas" (Braz, 2019, p. 50). É importante pontuar que este trabalho de conclusão de curso tem um recorte cultural e espacial bastante específico, definido a partir do entendimento do gênero como uma construção social e a observação, bastante pontual, de famílias de Campo Grande, Mato Grosso do Sul. Essa especificidade, contudo, não pode deixar de apontar a necessidade de uma atenção maior ao recorte de classe e raça, inserindo na discussão o fato de que a consideração do contexto econômico e de raça - e a maneira como eles são tratados socialmente - influenciam (modificando) definições, estereótipos, vivências, experiências de vida relacionadas à construção do gênero. Apesar de não ter sido uma preocupação inicial, enfatizamos que acreditamos ser impossível dissociar classe e raça de gênero. Assim, defendemos que a construção social de gênero se dá por meio da dinâmica das relações sociais e precisa ser observada e discutida segundo critérios (construídos) de categorização, na maioria das vezes sexistas, classistas e racistas.

A construção do futuro exige reconhecimento da memória que construímos e que reverenciamos, além do presente que ainda ignoramos como coletivo. Qualquer coisa que se desdobre a partir dessa negação não é futuro, mas uma repetição cruel e apática das realidades urbanas. A luta de grupos minorizados não descolou o reconhecimento da violação de direitos da busca pela emancipação via materialidade das demandas e de políticas institucionais. Esse é um erro de tradução (Macedo Júnior e Tavares, 2020).

Deste modo, considera-se que este trabalho é uma de tantas iniciativas que visam contribuir para os estudos de gênero, de forma a dialogar com a academia e com a comunidade externa, e com o intuito de levantar a bandeira de facilitadora do acesso à informação. O infográfico enquanto projeto experimental, assume um caminho de enriquecimento do campo profissional, por meio do desenvolvimento de pesquisas e metodologias. Acreditamos que a atividade jornalística, como parte integrante das Ciências Sociais Aplicadas, exige o aperfeiçoamento constante das práticas e essa proposta trouxe contribuições relevantes à experimentação, à distribuição do conteúdo, à necessidade de entender a infografia como produto do $\mathrm{DI}$, ao resultado de um processo transdisciplinar, entre outros aspectos.

\section{Agradecimento}

Ao curso de Jornalismo da UFMS pelo apoio e ensinamentos, às fontes que compuseram este projeto e a todos que colaboraram para o desenvolvimento de Corpos Prescritos, em especial a professora Dra Rafaella Lopes Pereira Peres. 


\section{Referências}

ADICHIE, Chimamanda Ngozi. Para educar crianças feministas: um manifesto. Trad. Denise Bottmann. 1 ed. São Paulo: Companhia das Letras, 2017. 94 p.

BRAZ, Ariadna Thalia Zortéa. Corpos Prescritos: infografia multimídia sobre a construção social de identidade de gênero. Trabalho de Conclusão de Curso apresentado ao curso de Jornalismo da Universidade Federal de Mato Grosso do Sul. Campo Grande: UFMS, 2019.

CAIRO, Alberto \& GINER, Juan A. Editors, artists chafe at the errors and hype in bin Laden death story graphics. 2011. Disponivel em: www.niemanwatchdog.org/index.cfm? fuseaction=Showcase.view\&\&showcaseid=152. Acesso em: 9 nov. 2019.

CANAVILHAS, João. João. Webjornalismo: 7 caraterísticas que marcam a diferença. [s. I.]: [s. n.], 2014. 196 p. ISBN 978-989-654-144-6. Disponível em: http://www.labcomifp.ubi.pt/ficheiros/20141204-201404_webjornalismo_jcanavi Ihas.pdf. Acesso em: 1 nov. 2019.

CARVALHO, Juliana e ARAGÃO, Isabella. Infografia: Conceito e Prática. InfoDesign - Revista Brasileira de Design da Informação. São Paulo, v. 9, n. 3. 2012, p. 160-177.

COIMBRA, Oswaldo. O texto da reportagem impressa: um curso sobre sua estrutura. 1 ed. São Paulo: Ática. 2004. 183 p.

COLLING, Ana Maria e TEDESCHI, Losandro Antôno (orgs.). Dicionário crítico de gênero. 2 ed. Dourados: UFGD, 2019. 748 p. Disponível em:

http://files.ufgd.edu.br/arquivos/arquivos/78/EDITORA/Catálogo/6.0.Dicionário crítico.L.T.11.01.19.Autor.FINAL.pdf. Acesso em: 4 maio 2019.

FUENTES, Rodolfo. A prática do design gráfico: uma metodologia criativa. trad. Oswaldo Antonio Rosiano. São Paulo: Rosari, 2006.

JESUS, Jaqueline Gomes de. Orientações sobre identidade de gênero: conceitos e termos: Guia técnico sobre pessoas transexuais, travestis e demais transgêneros, para formadores de opinião. 2. ed. rev. e aum. Brasília: [s. n.], 2012. 42 p. Disponível em: http://www.diversidadesexual.com.br/wp-content/uploads/2013/04/G\%C3\%8ANEROCONCEITOS-E-TERMOS.pdf. Acesso em: 1 nov. 2019.

LAGE, Nilson. A reportagem: Teoria e técnica de entrevista e pesquisa jornalística. [s. I.]: Record, 2001.

LIMA, Ricardo Cunha. O que é infografia jornalística? InfoDesign - Revista Brasileira de Design da Informação, São Paulo, v. 12, n. 1, p. 111-127, 2015.

MACEDO JÚNIOR, Gilson S. e TAVARES, Jéssica. Raça, gênero e sexualidade na construção das cidades. Nexo Jornal, 9 de dez. 2020. Disponível em: https://pp.nexojornal.com.br/ ponto-de-vista/2020/Raça-gênero-e-sexualidade-na-construção-das-cidades. Acesso em 12 jun. 2021.

MEDINA, Cremilda. Entrevista: o diálogo possível. 2 ed. São Paulo. 1990. 94 p.

MENDONÇA, Aline; PENTEADO, Cândida. A Identidade de Gênero no Jardim de Infância Que Construção Social?.[s.I.] Universidade de Madeira, 2010. 14p. Disponível em: http://www3.uma.pt/alicemendonca/conteudo/publica/candidapenteado.pdfhttp://www3.uma. pt/alicemendonca/conteudo/publica/candidapenteado. pdf. Acesso em: 2 fev 2019.

MORAES, Ary. Infografia: história e projeto. São Paulo: Blucher, 2013. 
ONU Mulheres et al. Precisamos falar com os homens? Uma jornada pela igualdade de gênero, Brasil, 2016. Disponível em: https://issuu.com/onumulheresbrasil/docs/ relat_rio_onu_eles_por_elas_pesqui. Acesso em: 4 maio 2019.

TEIXEIRA, Tattiana. Infografia e jornalismo: conceitos, análises e perspectivas. Salvador: EDUFBA, 2010. 120 p. Disponível em: repositorio.ufba.br/ri/handle/ri/20642. Acesso em: 1 nov. 2019.

\section{Sobre as autoras}

Ariadna Thalia Zortéa Braz, mestranda, UFMS, Brasil, e-mail <ariadna.t.braz@ufms.br> Rafaella Lopes Pereira Peres, PhD, UFMS, Brasil, <rafaella.peres@ufms.br> 